\title{
Application of Response Surface Methodology in Optimizing the Cold Compaction Parameters of Al-4Cu- $\mathrm{xAl} \mathrm{O}_{3}$ Composites
}

\author{
Ahmed E. Nassef ${ }^{1,2}$, S. M. El-Katatny ${ }^{3}$ and W.H. El_Garaihy ${ }^{3,4}$ \\ ${ }^{1}$ Department of Production Engineering \& Mechanical Design, Faculty of Engineering, Port-Said University, Egypt \\ ${ }^{2}$ Higher Institute of Engineering and Technology, Al-Arish, Egypt \\ ${ }^{3}$ Mechanical Engineering Department, Faculty of Engineering, Suez Canal University, Egypt \\ ${ }^{4}$ Mechanical Engineering Department, Unaizah College of Engineering, Qassim University, Saudi Arabia
}

\begin{abstract}
In this study, a quantitative evaluation approach is introduced to depict the effect of compact height to diameter ratio $(\mathrm{H} / \mathrm{D})$, compacting pressure, and alumina $\left(\mathrm{Al}_{2} \mathrm{O}_{3}\right)$ content of cold compacted discs on the relative density, Vickers hardness values, and compression properties of Al- $4 \mathrm{Cu}-\mathrm{xAl}_{2} \mathrm{O}_{3}$ composites. A central composite design is used for this experimental design. A full factorial core type of the central composite design is adopted. An empirical relationship has been formulated using response surface methodology to reflect the relevant function interrelations and optimize the different parameters. The developed relationships are examined for their adequacy and significance using several statistical criteria. Perfect agreement is found between the experiments and the numerical predictions in the range in which the results from design expert simulations are valid. The empirical relationship indicates that the compact $\mathrm{H} / \mathrm{D}$ ratio was found to be the most significant factor affecting the output parameters such as relative density and hardness. The experimental outcomes such as hardness value and yield strength showed a considerable enhancement by decreasing the compact $\mathrm{H} / \mathrm{D}$ ratio increasing the compacting pressure, and increasing the alumina content.
\end{abstract}

Keywords

Response surface methodology, Non-linear regression procedures, $\mathrm{Al}-4 \mathrm{Cu}$

\section{Introduction}

In recent decades, the powder metallurgy (PM) techniques have expanded more rapidly and are being widely used for sophisticated industrial applications. This is mainly due to the outstanding advantages, such as, facility of parts manufacture, material utilization, and economical advantages for large production [1,2]. Another significant advantage is the possibility to design the material properties by mixing different powder materials so that the final product achieves a specifically desired mechanical behavior [3]. Die powder compaction followed by densification of the compacted powder by sintering is a common process route in the production of industrial ceramics and hard metal components [4-6]. The process involves filling a powder formulation into a die, compression using rigid punches, and ejection from the die. Post-compaction operations such as sizing, sintering, coating, etc. are usually also applied depending on the application. One merit of PM is its high material usage as the parts are produced to near finished dimensions from the powder $[7,8]$. The compaction process can be undergoing a number of stages. In the first stage, namely, initial compaction, this involves particle rearrangements. The physical properties such as particle size, shape greatly influence this initial stage. This is followed by the elastic-plastic deformation, and here the mechanical properties and the quality of the particles are important factors, which control the compressibility behavior of the powder. This stage ends at packing densities around $80 \%$ to $90 \%$. The final stage of compaction is almost totally an upsetting of the bulk material. Hence, the work hardening of the particle affects the hardness of the final product $[1,4]$.

*Corresponding author: W H El Garaihy, Mechanical Engineering Department, Unaizah College of Engineering, Qassim University, King Abdulaziz St., 51911, Saudi Arabia, Tel: (+966)551108490

Accepted: July 10, 2019

Published online: July 12, 2019

Citation: Nassef AE, El-Katatny SM, El_Garaihy WH (2019) Application of Response Surface Methodology in Optimizing the Cold Compaction Parameters of $\mathrm{Al}-4 \mathrm{Cu}-\mathrm{xAl}_{2} \mathrm{O}_{3}$ Composites. Adv Metallurg Mater Eng 2(1):71-80 
Citation: Nassef AE, El-Katatny SM, El_Garaihy WH (2019) Application of Response Surface Methodology in Optimizing the Cold Compaction Parameters of Al-4Cu-xAl $\mathrm{O}_{3}$ Composites. Adv Metallurg Mater Eng 2(1):71-80

Metal matrix composites (MMC) have enhanced material properties in wear resistance, creep resistance, specific strength and specific modulus than pure metal matrix [9]. In manufacturing processes for composite powders, MMCs fabricated by PM routes exhibit superior mechanical properties due to lower manufacturing temperatures that lead to less destructive interfacial reactions between the matrix and reinforcement. In addition, PM has merits such as less residual voids and dissolved gases in products, a good interface between inclusions and metal matrix, and near-net shape forming of compacts [9-11]. Accordingly, the growing demand for light and high-performance materials has driven the proliferation of advanced aluminum alloys processed by PM [12].

The use of aluminum alloys is growing continuously in vehicles as a consequence of their low density and great corrosion resistance. These alloys, however, have limitations to use because of their inferior mechanical strength [13]. It is worth to mentioning here that, copper is an effective reinforcing element for aluminum, which forms with it different compounds and micro- and nanostructures [14]. Recent developments in the automobile, aerospace, defense and construction industries have led to increased interest in developing Al-Cu alloys with improved elevated temperature strength, stiffness and reduced density [15]. Addition of Cu up to about 5wt.\% in $\mathrm{Al}$ has resulted in good toughness and increased strength subjected to aging conditions $[16,17]$. It is worth to mentioning here that, ceramic particles such as alumina $\left(\mathrm{Al}_{2} \mathrm{O}_{3}\right)$ the most widely used materials for reinforcement of aluminum [18]. Aluminum matrix composite powders mainly reinforced with $\mathrm{Al}_{2} \mathrm{O}_{3}$ additions have been obtained in order to improve the wear behavior of aluminum alloy matrix and increase the hardness and compatibility of the matrix $[18,19]$. Accordingly, Short fiber or whisker reinforced aluminum alloy matrix composites have shown more advantages in mechanical and thermal properties because of the higher load transfer between reinforcement and matrix [20]. Normally, alumina particles are suspended in aluminum melts through PM process resulting in increasing the mechanical properties of the matrix [21].

In PM and ceramic industries, numerical modeling has been extensively used to optimize the compaction process, punch forces and tool design and to control the properties of the final product. The understanding, simulation and prediction of behavior of frictional contact are very important in both theory and practical applications [22]. In the current study, a quantitative procedure is adopted to explore the effect of the $\mathrm{Al}_{2} \mathrm{O}_{3}$ weight fraction, pressing pressure, and $\mathrm{H} / \mathrm{D}$ ratio on the physical and mechanical properties of $\mathrm{Al}-4 \mathrm{Cu}-\mathrm{xAl}_{2} \mathrm{O}_{3}$ composites, and to develop a general approach describing the dependence of the relative density, compressive properties and hardness of the composite on $\mathrm{Al}_{2} \mathrm{O}_{3}$ content and processing parameters. Response surface in terms of three dimensions and contours graphs were accordingly developed to enhance understanding of the functional dependence of the intended variables so as to be considered as database reference indicators in the design stages.

\section{Materials and Methods}

The matrix powder used consists of elemental blend of $\mathrm{Al}-$
$4 \mathrm{Cu}$ and fine particles of $\mathrm{Al}_{2} \mathrm{O}_{3}$ were used as reinforcement. The matrix used in this work is based on micron-powders of aluminum powders ( $99.9 \%$ purity, $\approx 25 \mu \mathrm{m}$ in average particles size) mixed with $4 \%$ wt. copper powders ( $99.9 \%$ purity, $\approx$ 10 in average particles size) and reinforcement of $\mathrm{Al}_{2} \mathrm{O}_{3}$ powders (99.99\% purity) with average particles size of $10 \mu \mathrm{m}$. The production of the $\mathrm{Al}-4 \mathrm{Cu}-\mathrm{xAl}_{2} \mathrm{O}_{3}$ composite was prepared by mixing the powders in a vacuum ambient within a glove box. The next step was to employ a turbula blender in mixing at a $96 \mathrm{rpm}$ rotational speed for three hours processing interval. The reinforcement contents used for the preparation of the composites were $2.5 \mathrm{wt} . \%, 5.0 \mathrm{wt} . \%, 7.5 \mathrm{wt} . \%$, and $10 \mathrm{wt} . \%$ based on previous experimental methodology $[23,24]$.

The alloy and the blended composites were uniaxially cold compacted in hardened steel molds under a hydraulic press, into cylindrical disc $20 \mathrm{~mm}$ in diameter with different height to diameter ratios (H/D) of $(0.75,1.0,1.25,1.5$, and 2.0). A high strength steel (w302) die with an inner diameter of $20 \mathrm{~mm}$ was used for powder pressing at room temperature. The compaction process was carried out at different compaction pressures of $(500,600,700,800$, and $900 \mathrm{MPa})$ for $60 \mathrm{~min}$. After compaction, sintering processes were carried out. Subsequently, heat treatment (solution heat treatment, natural aging) of the compacted composite was carried out. The sintering was performed by heating the discs at 560 ${ }^{\circ} \mathrm{C}$ for duration of 2 hours; the heating process was followed by furnace cooling process. Ageing process at a temperature of $160{ }^{\circ} \mathrm{C}$ for 2 hours followed by air cooling process was applied as a second sintering process.

Following the sintering process, the discs polished to a mirror-like shape. Density measurements were carried out on the $\mathrm{Al}-4 \mathrm{Cu}$ and reinforced discs using a digital densitometer using the Archimedean principle for density measurements. The theoretical density was calculated using the rule of mixtures. Vickers hardness $\left(H_{v}\right)$ values were measured on the disc's cross-sections using digital metallic Vickers's hardness tester. Testing was carried out on the surfaces under applied load of $10 \mathrm{~N}$ and a dwell time $15 \mathrm{sec}$ for each separate measurement. Compression tests were conducted on a $500 \mathrm{KN}$ universal testing machine. The discs were compressed at a strain rate of $1 \times 10^{-3} \mathrm{~S}^{-1}$ at room temperature.

The presented experimental design is obtained through Design Expert $11^{\circledR}$, which is a well-known specialized program in conducting design of experiments. A central composite design is used for this experimental design, where 3 numeric input factors were used: H/D (named as factor A), P (named as factor $\mathrm{B}$ ), and $\mathrm{Al}_{2} \mathrm{O}_{3}$ wt.\% (Named as factor $\mathrm{C}$ ). Each numeric input factor was set to 5 levels: plus, and minus alpha (axial points) set at 2, plus and minus 1 (factorial points) and the center point. A full factorial core type of the central composite design is adopted, having 4 center points and 20 non-center points, making the total number of required runs reach 24. The replications were designed to replicate the factorial points once, axial points twice, and the center points 4 times.

The responses were the 5 tested outputs as follow: 
Citation: Nassef AE, El-Katatny SM, El_Garaihy WH (2019) Application of Response Surface Methodology in Optimizing the Cold Compaction Parameters of Al-4Cu-xAl $\mathrm{O}_{3}$ Composites. Adv Metallurg Mater Eng 2(1):71-80

Table 1: The central composite design for three variables with five levels.

\begin{tabular}{|c|c|c|c|c|}
\hline Exp. No. & $\mathrm{Al}_{2} \mathrm{O}_{3}$ (wt. \%) & $H / D$ & Pressure (MPa) & Remark \\
\hline 1 & 2.5 & 1.5 & 800 & \multirow[t]{4}{*}{ Front Face Corners } \\
\hline 2 & 2.5 & 1.5 & 600 & \\
\hline 3 & 2.5 & 1.0 & 600 & \\
\hline 4 & 2.5 & 1.0 & 800 & \\
\hline 5 & 5.0 & 1.25 & 700 & \multirow[t]{2}{*}{ Repeated Center } \\
\hline 6 & 5.0 & 1.25 & 700 & \\
\hline 7 & 7.5 & 1.5 & 800 & \multirow[t]{4}{*}{ Back Face Corners } \\
\hline 8 & 7.5 & 1.5 & 600 & \\
\hline 9 & 7.5 & 1.0 & 600 & \\
\hline 10 & 7.5 & 1.0 & 800 & \\
\hline 11 & 5.0 & 1.25 & 700 & \multirow[t]{2}{*}{ Repeated Center } \\
\hline 12 & 5.0 & 1.25 & 700 & \\
\hline 13 & 5.0 & 2.0 & 700 & \multirow[t]{6}{*}{ Augment Experiments } \\
\hline 14 & 5.0 & 0.75 & 700 & \\
\hline 15 & 5.0 & 1.25 & 900 & \\
\hline 16 & 5.0 & 1.25 & 500 & \\
\hline 17 & 10.0 & 1.25 & 700 & \\
\hline 18 & 0.0 & 1.25 & 700 & \\
\hline 19 & 5.0 & 2.0 & 700 & \multirow[t]{6}{*}{ Repeated Augment Experiments } \\
\hline 20 & 5.0 & 0.75 & 700 & \\
\hline 21 & 5.0 & 1.25 & 900 & \\
\hline 22 & 5.0 & 1.25 & 500 & \\
\hline 23 & 10.0 & 1.25 & 700 & \\
\hline 24 & 0.0 & 1.25 & 700 & \\
\hline
\end{tabular}

Vicker's hardness, yield stress, compressive strength, fracture strain, and relative density. The central composite design for three variables with five levels was shown in Table 1. Based on the set of experimental data obtained from relative density, hardness and compression tests, the appropriate models were postulated, developed, and finally examined against its adequacy and significance.

\section{Results and Discussion}

\section{Effect of the processing parameters on the com- posite relative density}

A relationship was created between the $\mathrm{Al}-4 \mathrm{Cu} / \mathrm{Al}_{2} \mathrm{O}_{3}$ composites disc relative density $(R D)$, and other three independent variables, represented in $\mathrm{H} / \mathrm{D}, \mathrm{P}$, and $\mathrm{Al}_{2} \mathrm{O}_{3} \%$, using the fitting strategy mentioned previously, with the adoption of a set of experimental system described in Table 1. Numerical calculation and testing were taking place for the derivatives of the model versus the specified values of criteria. Iteration continued till reaching the finest model having the least residuals squares, related to the intended criteria. The results of this process led to the model:

$R D=83.62667+9.58667 \times A+0.006308 \times B+0.157667 \times C-0.001 \times A \times B-0.22 \times A \times C+0.0002 \times B \times$

$C-4.16 \times A^{2}-2 \times 10^{-6} \times B^{2}-0.0536 \times C^{2}$
The model F-value of 17.55 implies the model is significant. P-values less than 0.0500 indicate model terms are significant. The predicted $R^{2}$ of 0.6892 . Such excellent values confirmed the significance and adequacy of the developed model.

Figure 1 examines the goodness of the resulting equation where predicted (estimated) values yielded from Equation 1 were compared to the experimental counterparts $R D$. It can observe from Figure 1a that predicted values are close to its counterparts the experimental ones. The residuals distribution for the cold compacted discs $R D$ is shown in Figure $1 \mathrm{~b}$ where noting was observed against hypothesis that residuals are randomly distributed with zero mean.

Figure 2 indicates response surfaces expected values using model (1) for the Al-4Cu-5Al $\mathrm{O}_{3}$ wt.\%. The functional RD-H/ $D-P$ relationships are well qualitatively explained. It is shown a strong influence of both $H / D$ and $P$ on the compacted disc. However, surfaces indicate that $R D$ nonlinearly increases as the $H / D$ decreases and $P$ increases.

From Figure 2, it is clear that the $R D$ increases monotonically with increasing the compacting pressure, but the slope of the curve decreased, indicating a lower compressibility at higher pressure in the range of this study. Accordingly, in- 

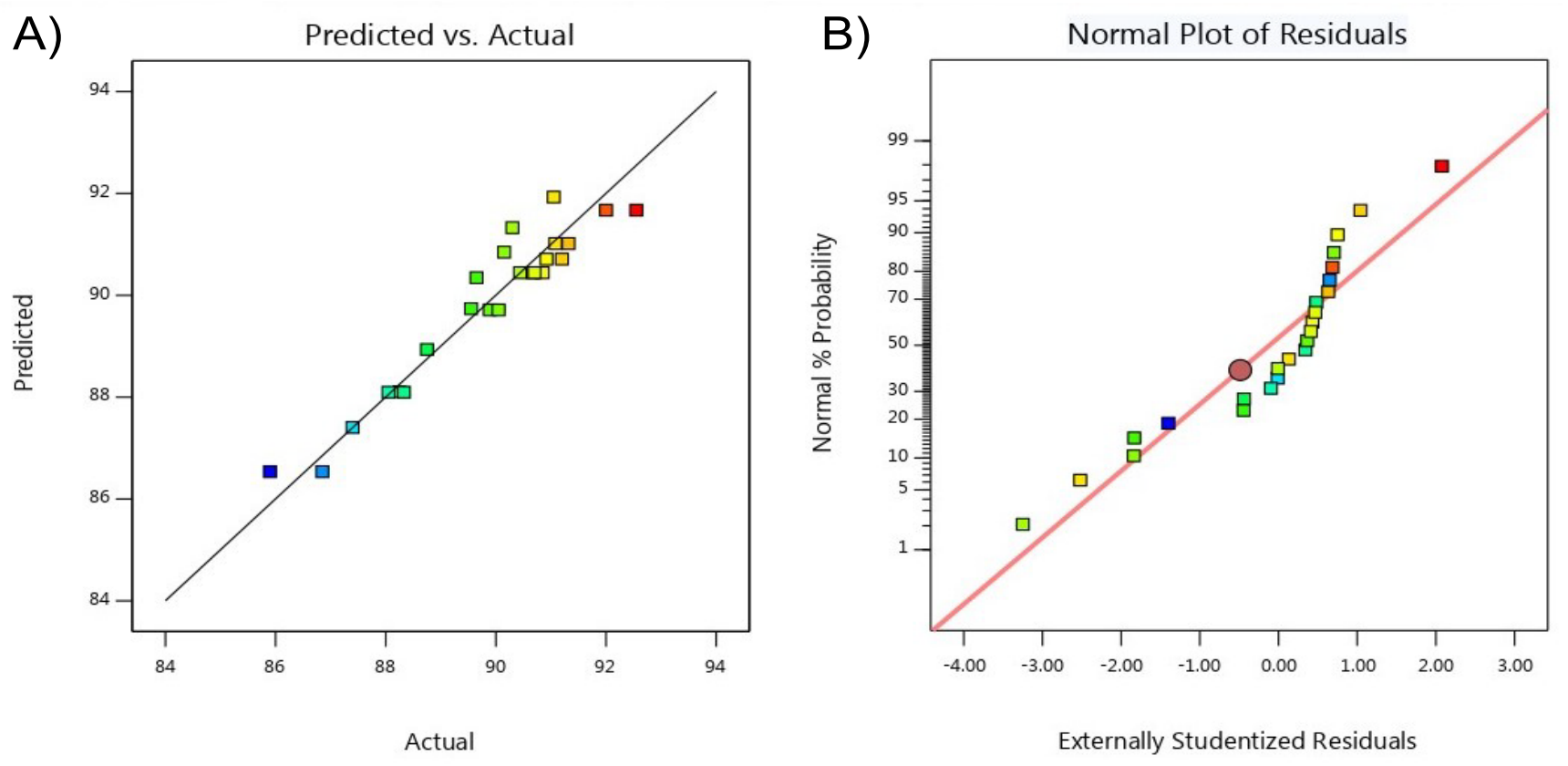

Figure 1: Experimental results vs. predicted of the $R D$ for the cold compacted discs as depicted at (a) and residuals distribution at (b).

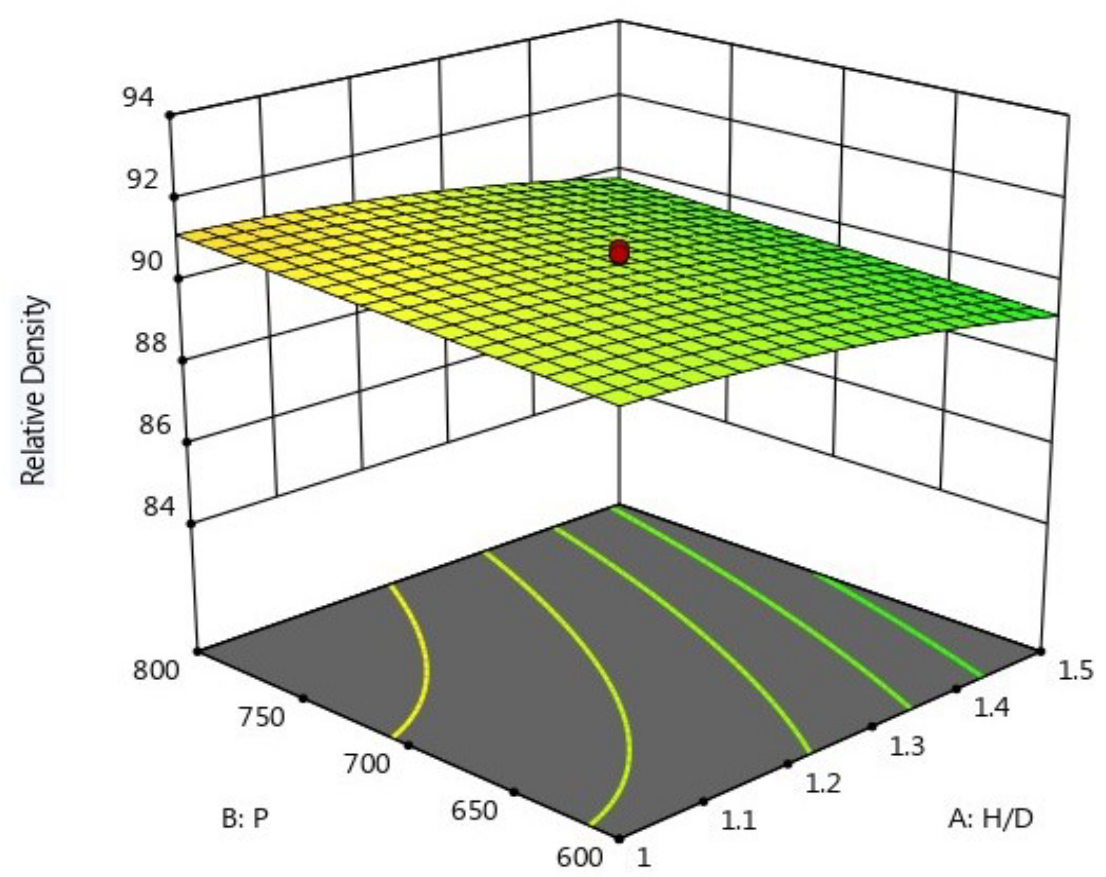

Figure 2: Response surface for $R D$ of $\mathrm{Al}-4 \mathrm{Cu} / 5 \mathrm{Al}_{2} \mathrm{O}_{3}$ wt.\% discs.

creasing the compacting pressure can assist all three porosity reduction mechanisms (movement of particles into voids, deformation of particles, and flatting of the microscopic and submicroscopic features on the particle surface). As compaction pressure increases, the distance between powder particles gets closer and the destruction of the oxide layer on the surface of powders is accelerated, resulting in increased the $R D$. Also it can be realized that, Figure 2 revealed improvement in the composites $R D$ with the decrease of $H / D$.
This is due to the pore closure during deformation and also performs the experienced rate of damping and resistance during deformation. Accordingly, as the applied die pressure increased, the density of samples decreased with increasing aspect ratios due to higher frictional force between the powder and the die-wall. In addition, from equation (1) it is clear that the lower the $\mathrm{Al}_{2} \mathrm{O}_{3}$ content, the higher of the densification for all compaction conditions. Accordingly, increasing of $\mathrm{Al}_{2} \mathrm{O}_{3}$ content leads to a decrease in relative density. This can 


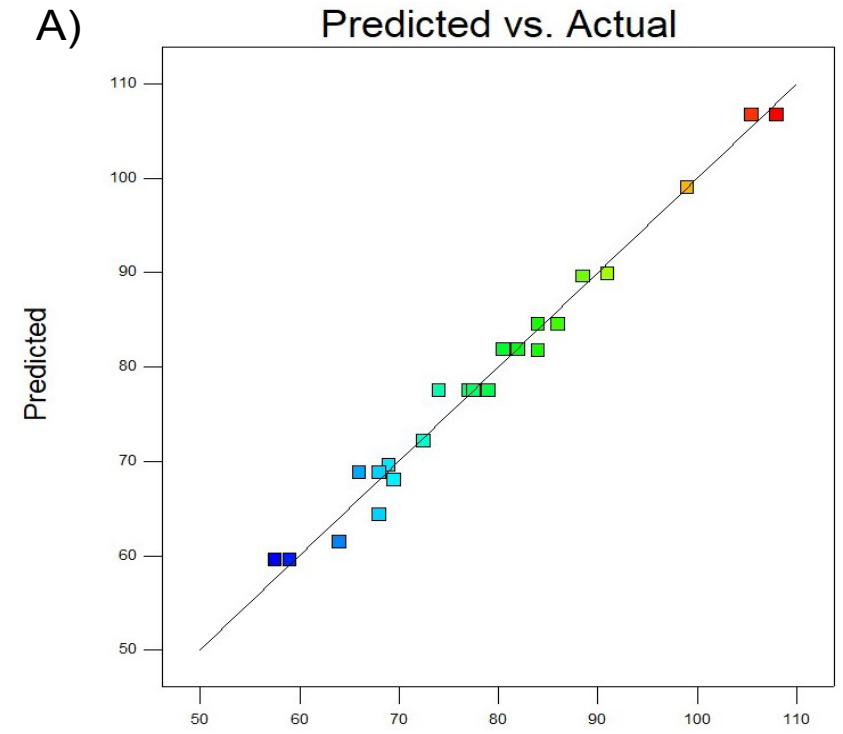

Actual

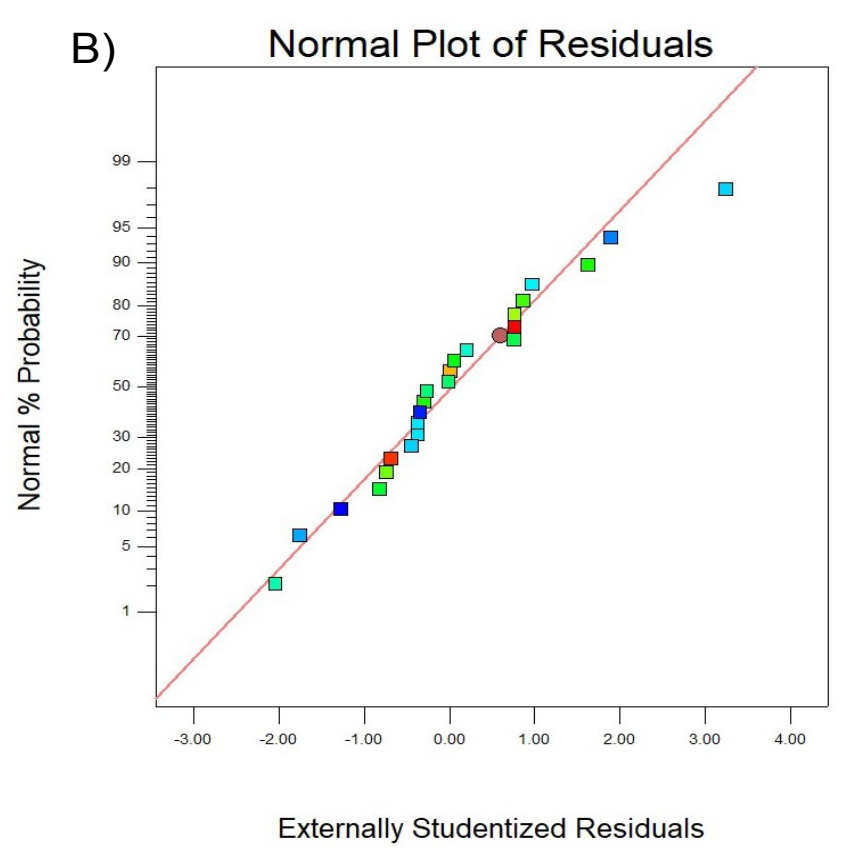

Externally Studentized Residuals

Figure 3: Experimental results vs. predicted data of the $H_{v}$-values for the cold compacted discs as depicted at (a) and residuals distribution at (b).

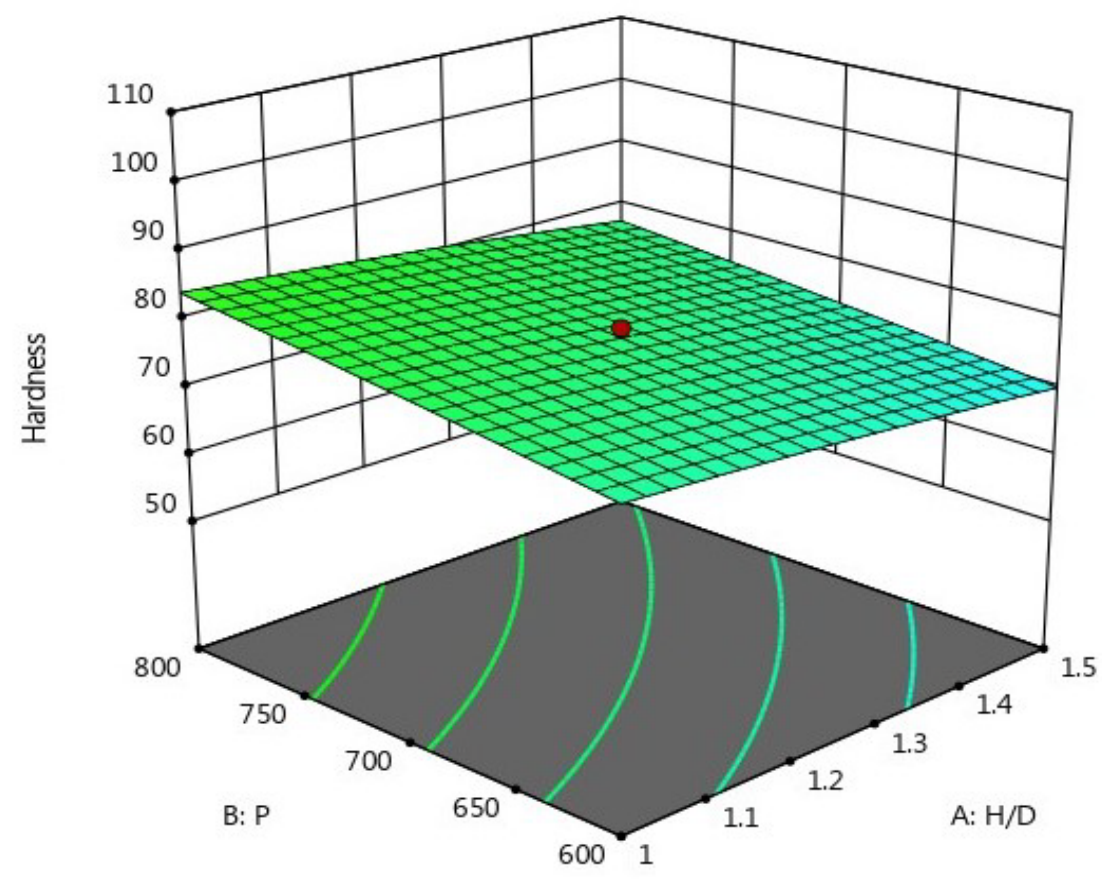

Figure 4: Response surface for $H_{v}$ of Al-4Cu/5 $\mathrm{Al}_{2} \mathrm{O}_{3}$ wt.\% discs.

be attributed to the introduction of the brittle of $\mathrm{Al}_{2} \mathrm{O}_{3}$ into the ductile matrix of Al-4Cu which leads to increasing the segregation between the reinforcement and matrix by increasing the reinforcement content. The possible mechanism may be explained by means of porosity evolution such that the fine pores at the particles interfaces have prevented the progress of densification which agreed with [25]. Accordingly, the $\mathrm{Al}_{2} \mathrm{O}_{3}$ reinforcement resulted in the formation of voids. In ad- dition, the volumetric voids increased by increasing the $\mathrm{Al}_{2} \mathrm{O}_{3}$ content. This reflected the decrease in the relative density as increasing the $\mathrm{Al}_{2} \mathrm{O}_{3}$ content.

In fact, for increased the hard particles content in the powder mixtures, soft Al alloy must undergo extra deformation to fill the voids between the hard inclusions. In other words, since there are fewer deforming particles in composite powders, the plastic particles must deform more 

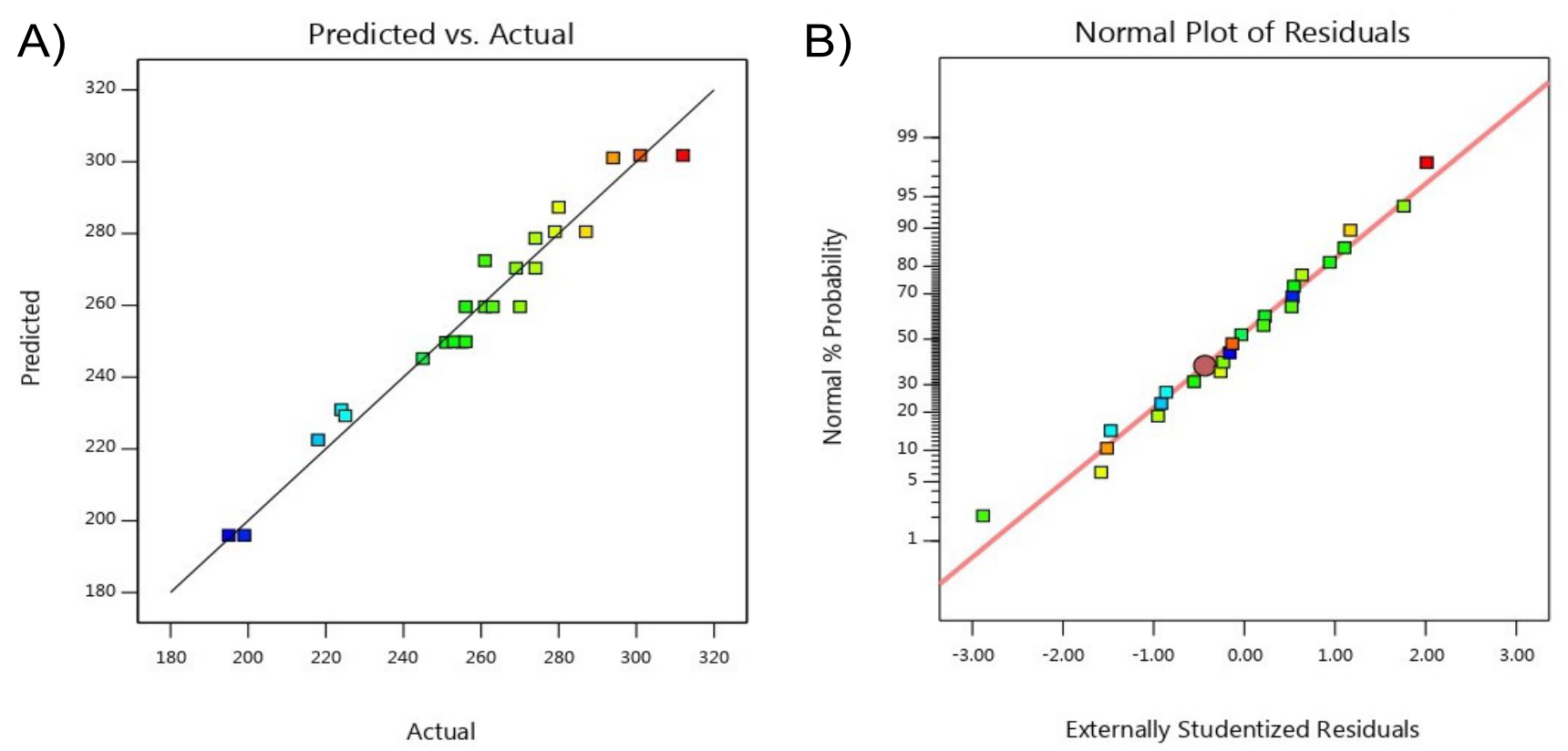

Figure 5: Experimental results vs. predicted of the yield strength for the cold compacted discs as depicted at (a) and residuals distribution at (b).

severely to achieve a given amount of densification requiring higher pressures. In addition, the formation of a continuous network of hard particles supports a portion of applied pressure and reduces the transmitted load to the soft plastic particles [26].

\section{Effect of the processing parameters on the composite hardness}

A functional interrelationship (2) was established between the dependent variable, the alloy of $H_{v}$-values, and the influential independent variables, $\mathrm{H} / \mathrm{D}, \mathrm{P}$, and $\mathrm{Al}_{2} \mathrm{O}_{3} \%$. The best model was in the form:

$H_{v}=6.01042+24.5 \times A+0.079375 \times B+4.20833 \times C-0.0125 \times A \times B-2.10 \times A \times C+0.00125 \times B \times C-$

$7 \times A^{2}-0.000022 \times B^{2}+0.225 \times C^{2}$

With good statistical criteria of $R^{2}$ of 0.9452 . The model F-value of 95.47 implies the model is significant. The P-value is less than 0.0500 which indicate that the model terms are significant. Figure $3 a$ is dedicated to indicating how predicted (estimated) values are close to its counterpart experimental values. In addition, the residuals distribution for the $H_{v}$ -values is shown in Figure $3 b$.

Figure 4 indicates response surfaces expected values using model (2) for the Al-4Cu- $5 \mathrm{Al}_{2} \mathrm{O}_{3}$ wt.\%. The functional $H_{v}-\mathrm{H} / \mathrm{D}-\mathrm{P}$ relationships are well qualitatively explained. It is shown a strong influence of both $H / D$ and $P$ on the compacted disc. However, surfaces indicate that $H_{v}$ nonlinearly increases as the $H / D$ decreases and $P$ increases. Figure 4 revealed that, increasing of the compacting pressure resulted in a significant increase in the $H_{v}$-value of the cold compacted discs. Moreover, decreasing the H/D ratio demonstrated an additional improvement in the $H_{v}$-value of the Al-4Cu- $\mathrm{Al}_{2} \mathrm{O}_{3}$ composite discs. The increase in the hardness value of the deformed specimen by increasing the compacting pressure and decreasing the H/D ratio can be attributed to grain interlocking and reduction in the pore size. From equation (2) it is clear that all composite alloys are characterized by a higher hardness compared to the nonreinforced one. In addition, increasing the reinforcement content resulted in increasing the $H_{v}$-values. The presence of the $\mathrm{Al}_{2} \mathrm{O}_{3}$ increased the composite hardness as they carry some of the load applied to the material (load transfer from the matrix to the reinforcement due to the difference in the elastic constant). The increase in the $H_{v}$-values of the composite can be attributed to the high hardness of the reinforcement. So mainly the interaction is either aluminum with aluminum particles which adhere properly or aluminum with $\mathrm{Al}_{2} \mathrm{O}_{3}$ in which adhesion is enhanced by the presence of $\mathrm{Al}_{2} \mathrm{O}_{3}$ particle which agreed with Khairaldien, et al. [27].

\section{Effect of the processing parameters on the composite compressive properties}

Similar fitting procedures and strategy were employed to develop a functional interrelationship between $\sigma_{y}$; model (3), the CS; model (4), and $\varepsilon_{f}$; model (5) as dependent variables and $\mathrm{H} / \mathrm{D}, \mathrm{P}$, and $\mathrm{Al}_{2} \mathrm{O}_{3} \%$ as influential independent variables for $\mathrm{AA6061-} \mathrm{Al}_{2} \mathrm{O}_{3}$ composites.

$\sigma_{y}=155.47917-20.33333 \times A+0.13 \times B+18.48333 \times C-0.075 \times A \times B-2.6 \times A \times C$

with good statistical criteria of $\mathrm{R}^{2}$ of 0.8739 . The model F-value of 41.52 implies the model is significant. The P-value is less than 0.0500 which indicate that the model terms are significant. Figure $5 \mathrm{a}$ is dedicated to indicating how predicted (estimated) values are close to its counterpart experimental values. In addition, the residuals distribution for the $\sigma_{y}$ is shown in Figure 5b. In addition, Figure 6 indicates response surfaces expected values using model (3) for the Al-4Cu$5 \mathrm{Al}_{2} \mathrm{O}_{3}$ wt.\%. The functional $\sigma_{y}-\mathrm{H} / \mathrm{D}-\mathrm{P}$ relationships are well 


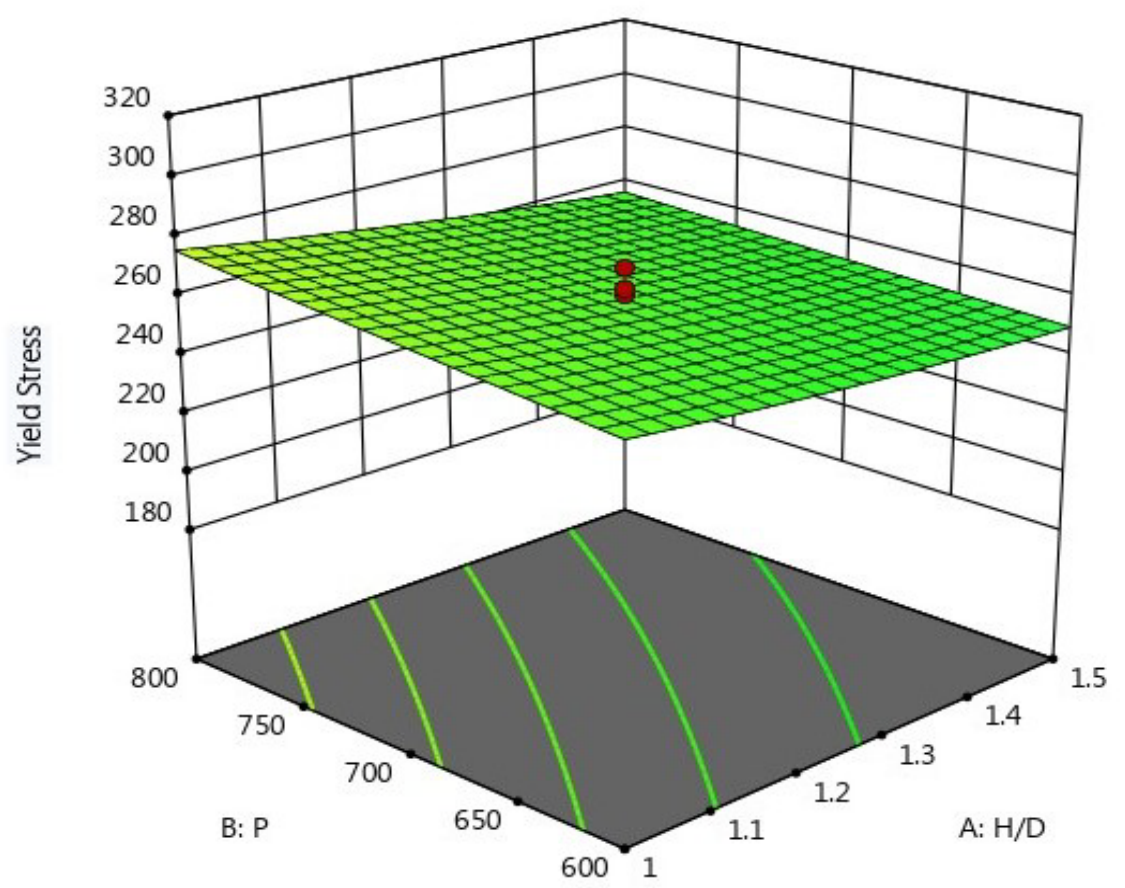

Figure 6: Response surface for yield strength of $\mathrm{Al}-4 \mathrm{Cu} / 5 \mathrm{Al}_{2} \mathrm{O}_{3} \mathrm{wt} . \%$ discs.

A)

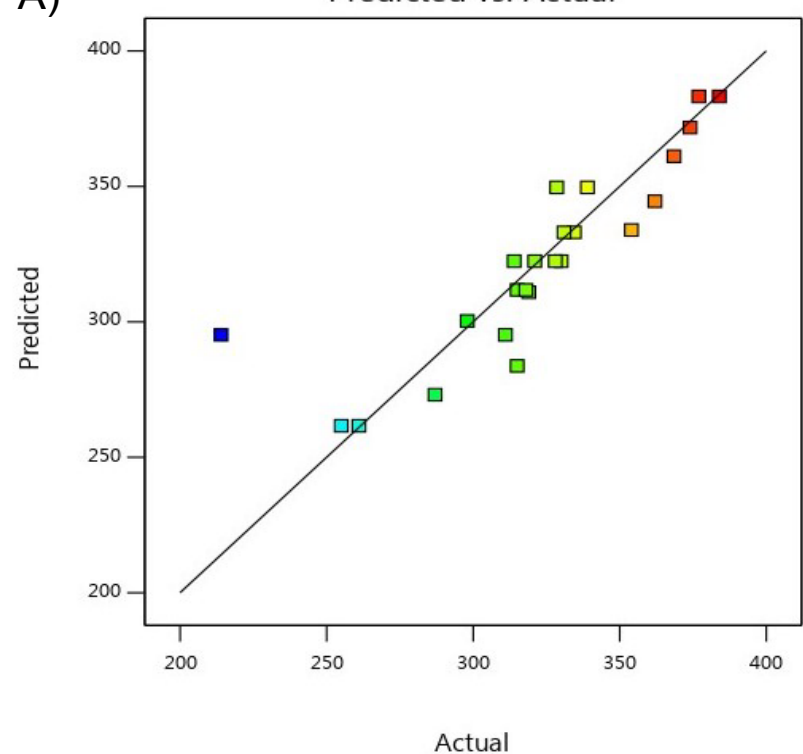

B)

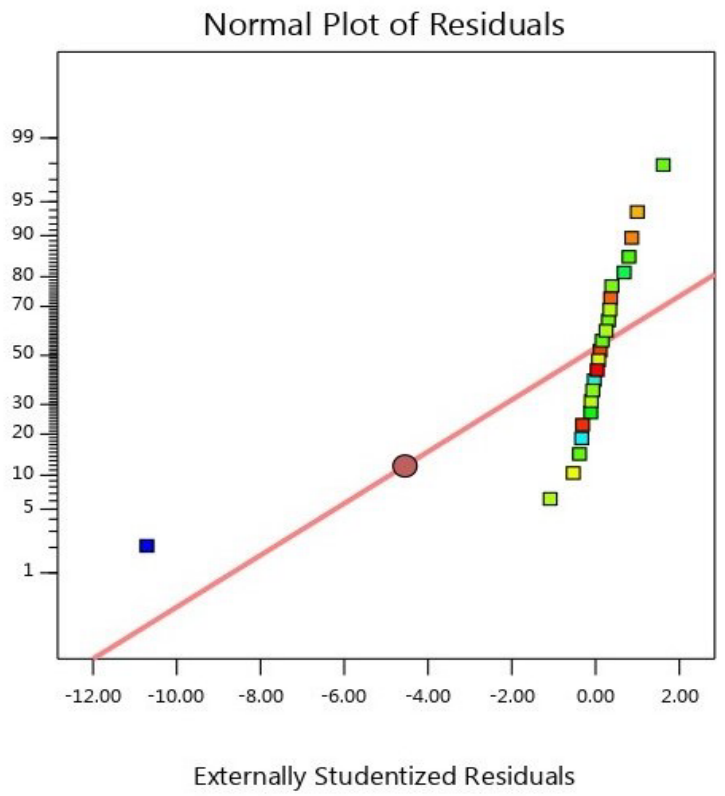

Figure 7: Experimental results vs. predicted of the compressive strength for the cold compacted discs as depicted at (a) and residuals distribution at (b).

qualitatively explained.

The compressive strength results led to the model:

$\sigma_{c}=292.47917-54.41667 \times A+0.053125 \times B+12.15833 \times C$

With $\mathrm{R}^{2}$ of 0.5918 . The model F-value of 18.73 implies the model is significant. The P-value is less than 0.0500 which indicate that the model terms are significant. Figure 7 shows the experimental and the counterpart predicted results comparison. Also, residual values and distribution for each parameter are included. In addition, Figure 8 indicates response surfaces expected values using model (4) for the Al$4 \mathrm{Cu}-5 \mathrm{Al}_{2} \mathrm{O}_{3} \mathrm{wt} . \%$.

In addition, the fracture strain results led to the model: $\varepsilon_{f}=15.3+4.43333 \times A-0.01525 \times B-0.543333 \times C+0.002 \times A \times B+0.48 \times A \times C-0.0003 \times B \times C$ $2.4 \times A^{2}+8.75 \times 10^{-6} \times B^{2}-0.044 \times C^{2}$

with $\mathrm{R}^{2}$ of 0.9087 . The model F-value of 55.45 implies the model is significant. The P-value is less than 0.0500 which indicate that the model terms are significant. Accordingly, 


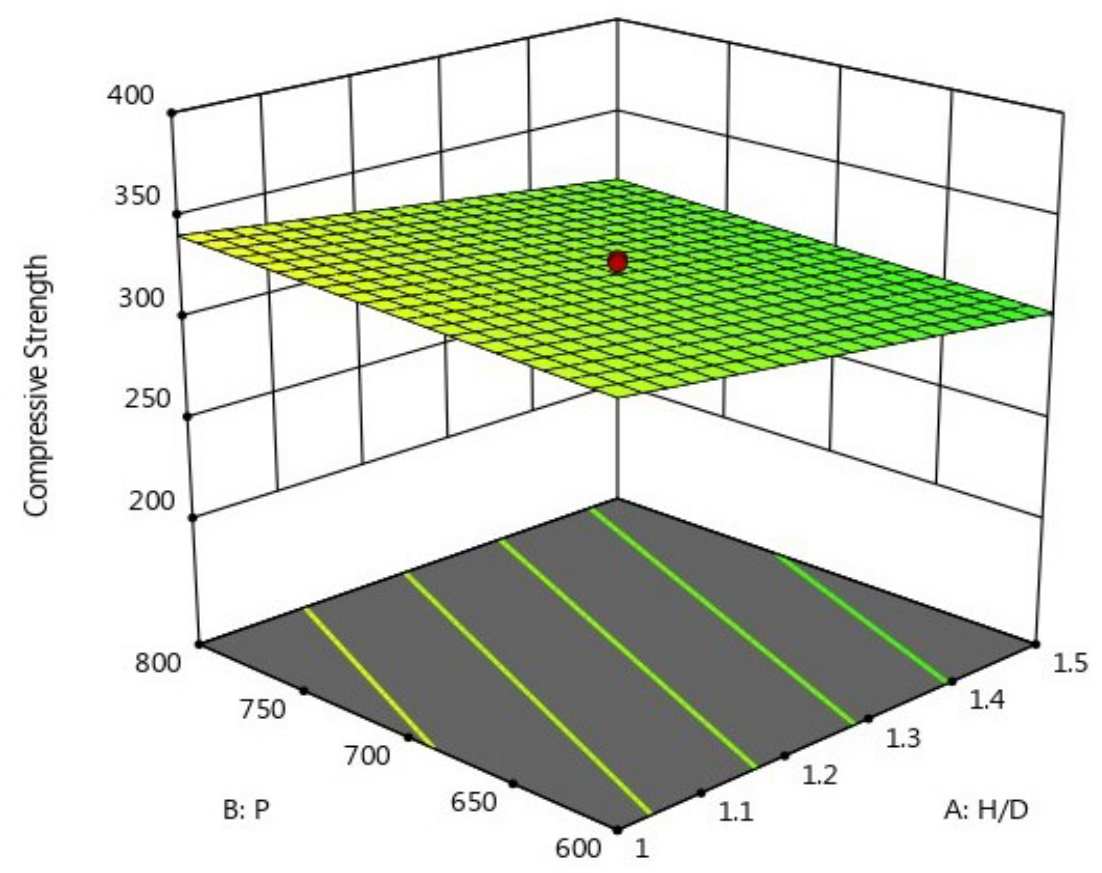

Figure 8: Response surface for compressive strength of $\mathrm{Al}-4 \mathrm{Cu} / 5 \mathrm{Al}_{2} \mathrm{O}_{3}$ wt.\% discs.
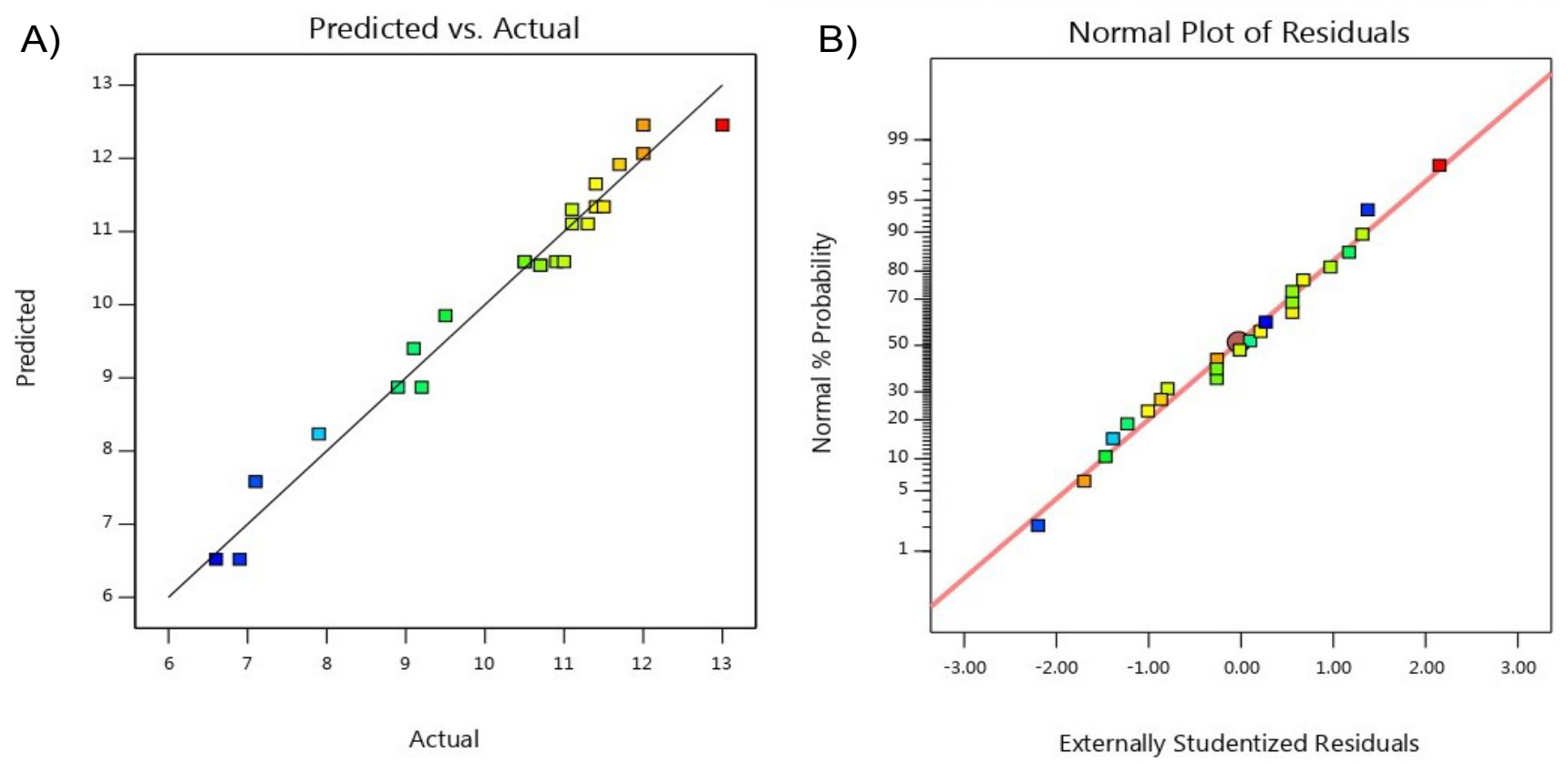

Figure 9: Experimental results vs. predicted of the fracture strain for the cold compacted discs as depicted at (a) and residuals distribution at (b).

it is clear that the developed models (3-to-5) are regarded as significant and satisfactory for the relevant functional interrelationship representation. Figure 9a, shows the similarity between the predicted (estimated) values and experimental values for the fracture strain. In addition, the residuals distribution of the fracture strain is shown in Figure $9 b$. In addition, Figure 10 indicates contours maps expected values using model (5) for the $\mathrm{Al}-4 \mathrm{Cu}-5 \mathrm{Al}_{2} \mathrm{O}_{3}$ wt.\%.
From models (3-5) it can be concluded that, increasing the compacting pressure resulted in an increase in both yield and the compressive strength coupled with decreasing of the fracture strain of the cold compacted discs. Out of contrary, decreasing the value of H/D of the compacted discs resulted in increasing both yield and compressive strength of the Al$4 \mathrm{Cu}-\mathrm{Al}_{2} \mathrm{O}_{3}$ discs. Accordingly, the improvement of the hardness and the compressive strength can be attributed to the enhancement of the density due to increasing the compact- 


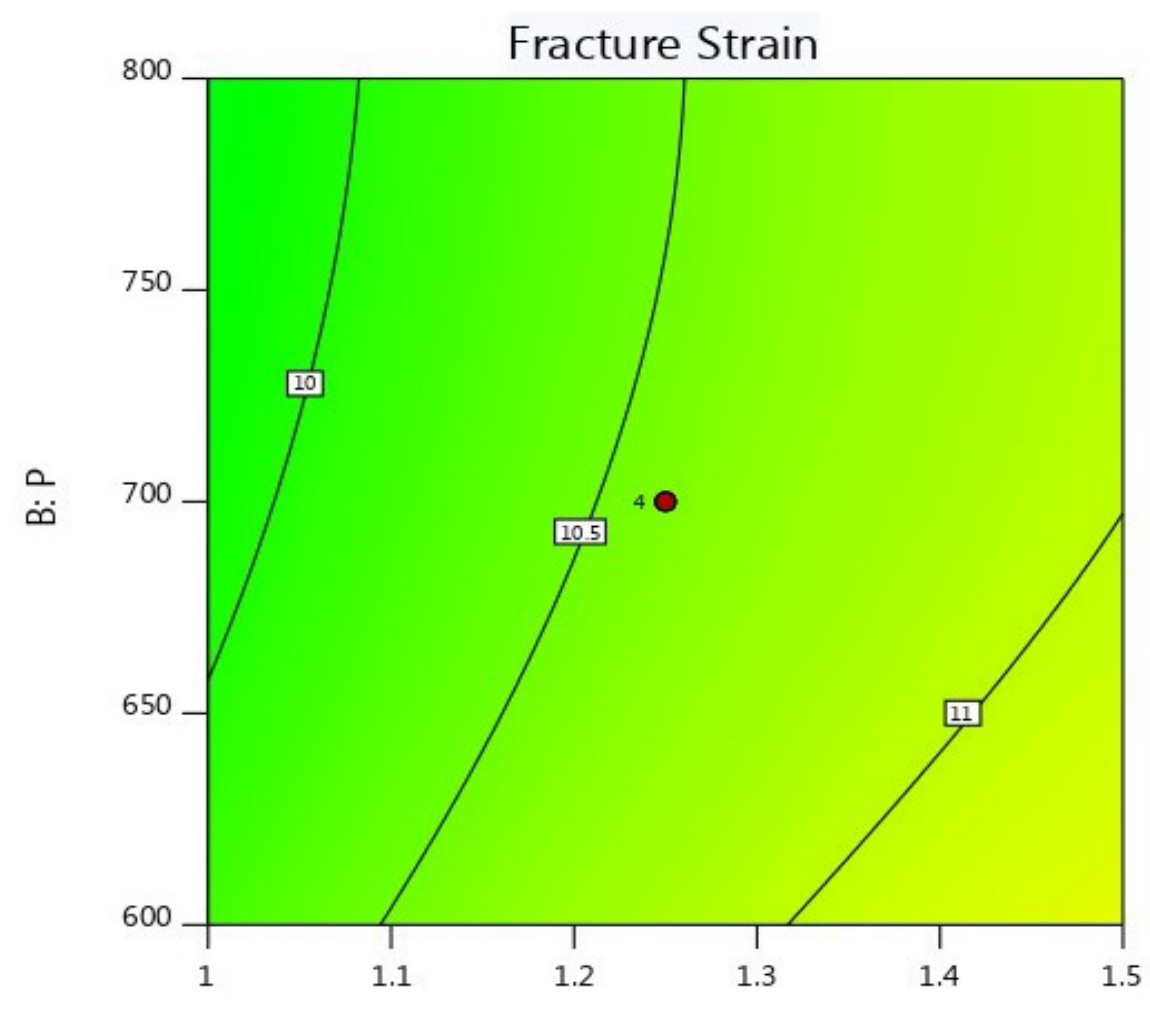

A: H/D

Figure 10: Contours maps for fracture strain of $\mathrm{Al}-4 \mathrm{Cu} / 5 \mathrm{Al}_{2} \mathrm{O}_{3}$ wt.\% discs.

ing pressure or decreasing the H/D ratio. In addition, it is clear that the results of compressive properties characterization showed that the $\mathrm{Al}_{2} \mathrm{O}_{3}$ particles are helpful in enhancing the compressive strength. The significant increase in compressive strength of alumina reinforced $\mathrm{Al}-4 \mathrm{Cu}$ composite could be attributed to the grain refinement resulted from the addition of the alumina particles, the presence of reasonably distributed harder particulates, strengthening arises from increase in dislocation density of the matrix, and load transfer from matrix to reinforcement/second phases [28]. The $\mathrm{Al}_{2} \mathrm{O}_{3}$ particles distort the crystal lattice of the Al-4Cu matrix, hinder dislocation mobility and hence strengthen the alloy. On the other hand, the compression test results revealed that the ceramic phase addition significantly lowered the plasticity of the composite.

\section{Conclusions}

In this study, an evaluation quantitative approach is introduced not only to depict the plain individual effect of the influence of compact aspect ratio, compaction pressure, and alumina content on the relative density, Vickers hardness values, and compression properties of the sintered Al$4 \mathrm{Cu}-\mathrm{xAl}_{2} \mathrm{O}_{3}$ composites is obtained. A central composite design is used for this experimental design. The developed relationships are examined for its adequacy and significance using several statistical criteria. Excellent agreement is found between the experiments and the numerical predictions in the range where results from design expert simulations are valid. The next deductions could be concluded out of the performed effort of this article:

1. The empirical relationship indicates that the compact aspect ratio was found to be the most significant factor affecting the output parameters such as relative density and hardness.

2. The experimental outcomes such as hardness value, and yield strength recorded a considerable enhancement by decreasing the compact aspect ratio, increasing the compacting pressure.

3. Increasing $\mathrm{Al}_{2} \mathrm{O}_{3}$ content is found to reduce the relative density and to increase the hardness of the composites.

\section{References}

1. HA Al-Qureshi, MRF Soares, D Hotza, et al. (2008) Analyses of the fundamental parameters of cold die compaction of powder metallurgy. Journal of Materials Processing Technology 199: 417-424.

2. R Narayanasamy, T Ramesh, KS Pandey, et al. (2008) Effect of particle size on new constitutive relationship of aluminium-iron powder metallurgy composite during cold upsetting. Materials and Design 29: 1011-1026.

3. JF Jerier, B Hathong, V Richefeu, et al. (2011) Study of cold powder compaction by using the discrete element method. Powder Technology 208: 537-541.

4. E Olsson, PL Larsson (2013) A numerical analysis of cold powder compaction based on micromechanical experiments. Powder Technology 243: 71-78. 
5. I Aydln, BJ Briscoe, KY Sanliturk (1994) Density distributions during the compaction of alumina powders: A comparison of a computational prediction with experiment. Computational Materials Science 3: 55-68.

6. D Poquillon, J Lemaitre, V Baco-Carles, et al. (2002) Cold compaction of iron powders-relations between powder morphology and mechanical properties Part I: Powder preparation and compaction. Powder Technology 126: 65-74.

7. Xue-Kun Sun, Shao-Jie Chen, Jian-Zhong Xu, et al. (1999) Analysis of cold compaction densification behavior of metal powders. Materials Science and Engineering A 267: 43-49.

8. SA Rolland, P Mosbah, DT Gethin, et al. (2012) Lode dependency in the cold die powder compaction process. Powder Technology 221: $123-136$

9. KT Kim, SC Lee, HS Ryu (2003) Densification behavior of aluminum alloy powder mixed with zirconia powder inclusion under cold compaction. Materials Science and Engineering A 340: 41-48.

10. M Moazami-Goudarzi, F Akhlaghi (2013) Effect of nanosized $\mathrm{SiC}$ particles addition to $\mathrm{CP} \mathrm{Al}$ and $\mathrm{Al}-\mathrm{Mg}$ powders on their compaction behavior. Powder Technology 245: 126-133.

11. T Varol, A Canakci, ED Yalcin (2017) Fabrication of NanoSiCReinforced Al2024 matrix composites by a novel production method. Arab J Sci Eng 42: 1751-1764.

12. F Bardi, M Cabibbo, E Evangelista, et al. (2003) An analysis of hot deformation of an Al-Cu-Mg alloy produced by powder metallurgy. Materials Science and Engineering 339: 43-52.

13. A Gokce, F Findik, AO Kurt (2011) Microstructural examination and properties of premixed Al-Cu-Mg powder metallurgy alloy. Materials Characterization 62: 730-735.

14. LE Agureev, VI Kostikov, Zh V Yeremeyeva, et al. (2016) Powder aluminum composites of Al-Cu system with micro-additions of oxide nanoparticles. Inorganic Materials: Applied Research, 27: 687-690.

15. AP Kumar, VMS Muthaiah, S Mula (2017) Effect of Nb, Y and Zr on thermal stability of nanocrystalline $\mathrm{Al}-4.5 \mathrm{wt} . \% \mathrm{Cu}$ alloy prepared by mechanical alloying. Journal of Alloys and Compounds 722: 617-627.

16. $M$ Li, H Wang, $Z$ Wei, et al. (2010) The effect of $Y$ on the hottearing resistance of $\mathrm{Al}-5 \mathrm{wt} . \% \mathrm{Cu}$ based alloy. Materials \& Design 31: 2483-2487.
17. S Devaraj, S Sankaran, R Kumar, et al. (2014) Influence of hot isostatic pressing on the microstructure and mechanical properties of a Spray-Formed Al-4.5 wt.\% Cu alloy. JMEPEG 23: 1440-1450.

18. EM Ruiz-Navas, JB Fogagnolo, F Velasco, et al. (2006) One step production of aluminum matrix composite powders by mechanical alloying. Composites Part A: Applied Science and Manufacturing 37: 2114-2120.

19. A Canakci, T Varol, F Erdemir (2016) The effect of flake powder metallurgy on the microstructure and densification behavior of $\mathrm{B}_{4} \mathrm{C}$ Nanoparticle-Reinforced $\mathrm{Al}-\mathrm{Cu}-\mathrm{Mg}$ alloy matrix nanocomposites. Arab J Sci Eng 41: 1781-1796.

20. G Lin, X Hong-yu, Y Kuai, et al. (2007) Aging behavior of $\mathrm{Al}_{2} \mathrm{O}_{3}$ short fiber reinforced Al-Cu alloy composites. Trans Nonferrous Met Soc China 17: 1018-1021.

21. M Hoseinia, M Meratian (2009) Fabrication of in situ aluminumalumina composite with glass powder. Journal of Alloys and Compounds 471: 378-382.

22. AR Khoei, S Keshavarz, AR Khaloo (2008) Modeling of large deformation frictional contact in powder compaction processes. Applied Mathematical Modelling 32: 775-801.

23. SM El Katatny (2015) Modeling and experimental study of powder compaction. M.Sc. Thesis, Port Said University, Egypt.

24. AE Nassef, GA Ebrahim, AA El-Baghdady (2003) Mechanical and microstructure characteristics of $\mathrm{Al}-4 \mathrm{Cu} / \mathrm{Al}_{2} \mathrm{O}_{3} \mathrm{MMCs}$ produced via PM techniques. Journal of Engineering and Applied Science 50: 371-386.

25. SC Lee, KT Kim (2002) Densification behavior of aluminum alloy powder under cold compaction. International Journal of Mechanical Science 44: 1295-1308.

26. Mohammad Moazami-Goudarzi, Farshad Akhlaghi (2013) Effect of nanosized SiC particles addition to $\mathrm{CP}$ Al and Al-Mg powders on their compaction behavior. Powder Technology 245: 126-133.

27. WM Khairaldien, AA Khalil, MR Bayoumi (2007) Production of aluminum-silicon carbide composites using powder metallurgy at sintering temperatures above the aluminum melting point. Journal of Testing and Evaluation 35.

28. A Fathy, F Shehata, M Abdelhameed, et al. (2012) Compressive and wear resistance of nanometric alumina reinforced copper matrix composites. Materials and Design 36: 100-107.

DOI: $10.36959 / 508 / 398$

Copyright: (C) 2019 Nassef AE, et al. This is an open-access article distributed under the terms of the Creative Commons Attribution License, which permits unrestricted use, distribution, and reproduction in any medium, provided the original author and source are credited. 